\title{
IMPLEMENTASI PROGRAM PENGELOLAAN PENYAKIT KRONIS (PROLANIS): STUDI KASUS DI PUSKESMAS CIPUTAT
}

\author{
Nazarwin Saputra ${ }^{1}$, Chairunissa ${ }^{2}$ \\ ${ }^{1,2}$ Program Studi Kesehatan Masyarakat Universitas Muhammadiyah Jakarta \\ Email: nazarwinepid@gmail.com ${ }^{1}$; nazarwin.saputra@umj.ac.id ${ }^{1}$
}

\begin{abstract}
There has been an epidemiological transition that the trend of cases of infectious diseases has now turned to non-communicable diseases. Social Insurance administration organization and first-level health facilities (Puskesmas) work together to reduce the risk factors for Non-Communicable Diseases with chronic disease management program, but non-communicable diseases continue to increase. The researcher aims to examine the implementation of chronic disease management program in the Ciputat district Health center Office Area. The key informants in this research are the person in charge of the program and the program implementer. The analysis used in this study is content analysis. This research was also triangulated to prevent bias. The results of this study are the absence of prolanist special management training for officers such as surveillance systems, there are no measurable indicators of program success in the Ciputat Health Center such as from the extension program (increased knowledge), gymnastics and epidemiological measures of diseases such as fatality and morbidity, there is no SOP reporting and private first level health facility do not have awareness to report data to puskesmas. Researchers suggest to conduct training in management of chronic disease management, create tools to measure program success and create workshops to discuss SOPs for reporting specifically from private first level health facility to the government in this case puskesmas.
\end{abstract}

Keywords:, chronic, disease, implementation, management, program

\section{PENDAHULUAN}

Di era revolusi industri 4.0 sekarang ini telah terjadi transisi epidemiologi dimana trend kasus kejadian penyakit tidak menular lebih signifikan dibandingkan dengan penyakit menular. Hal tersebut dikarenakan berbagai macam faktor diantaranya perilaku berisiko terhadap kesehatan masyarakat. Hasil studi riset kesehatan dasar ditemukan hasil bahwa kasus hipertensi mengalami peningkatan kasus dari 7,6\% pada tahun 2007 meningkat menjadi 9,5\% tahun 2013. Pada kasus stroke juga mengalami peningkatan kasus dari 8,3 per 1000 penduduk pada tahun 2007 meningkat menjadi 12,1 per 1000 penduduk tahun 2013. Kasus diabetes juga senada dengan kasus hipertensi dan stroke yang mengalami peningkatan kasus. Kasus diabetes meningkat dari 1,1\% tahun 2007 menjadi $1,1 \%$ pada tahuun 2013 (Balitbangkes Kemenkes, 2013). Jika kasus tersebut tidak ditangani secara serius akan berdampak sistemik diantaranya bisa terjadi out break serta menurunkan derajat kesehatan masyarakat di suatu bangsa.

Banyak faktor yang mempengaruhi peningkatan kasus penyakit tidak menular diantaranya faktor genetik, lingkungan gaya hidup yang tidak sehat seperti merokok, konsumsi alkohol, pola diet dan kurang aktifitas. Faktor tersebut seyogyanya di kontrol untuk menurunkan morbiditas dan mortalitas kasus penyakit menular. Pemerintah dengan lintas sektor perlua adanya kerjasama mengembangkan 
strategi pada pencegahan dan pengendalian penyakit tidak menular seperti DM dan penyakit kardiovaskular (Warnegara E, 2016).

Pemerintah membuat program pengelolaan program penyakit kronis sebagai upaya pengendalian risiko dan menekan kejadian kasus penyakit tidak menular begitu juga dan dalam rangka mencapai universal health converege BPJS juga membuat program untuk para pesertanya yang menderita penyakit kronis guna mereduksi kejadian kasus penyakit tidak menular yang dikenal dengan program pengelolaan penyakit kronis yang disingkat dengan Prolanis. Prolanis sendiri adalah sistem pelayanan kesehatan dan pendekatan pro aktif yang dilaksanakan secara terintegrasi serta melibatkan peserta, fasiltas kesehatan dan BPJS dalam rangka emmelihara kesehatan pada peserta BPJS kesehatan yang menderita penyakit kronis. Dengan tujuan untuk mencapai kualitas hidup yang optimal dengan biaya pelayanan kesehatan yang efektif. Yang perlu ditekankan adalah hanya untuk peserta bpjs yang menderita penyakit kronis, bukan pasien umum (Badan Penyelenggaraan Jaminan Sosial Kesehatan, 2016).

Berdasarkan analisa dan survey di tataran pelayanan maka Dinas Kesehatan telah menentukan isu-isu strategisnya yaitu salah satunya Target Universal Coverage program Jaminan Kesehatan Nasional
(JKN) pada tahun 2019. Maka untuk mencapai hal tersebut FKTP yang ada di tangerang selatan sudah bekerja sama dengan BPJS. Program jaminana sosial menjamin pemeliharaan kesehatan serta pemenuhan kebutuhan dasar kesehatan yang diselenggarakan nasional secara gotong royong wajib oleh seluruh rakyat indonesia dengan membayar iuran berkala atau iurannya dibayar olen pemerintah kepada penyelenggara jaminan sosial nirlaba (Putri, 2014).

Puskesmas Ciputat merupakan salah satu puskesmas yang ada di wilayah kerja tangerang selatan yang melaksanakan Prolanis. Puskesmas Ciputat merupakan salah satu FKTP di tangerang selatan yang menjalankan program prolanis. Kepesertaan prolanis di puskesmas ini mencapai lebih dari 125 peserta. Namun kasus penyakit tidak menular kecenderungannya masih tinggi dengan 4202 kasus pada tahun 2015 (Puskesmas Ciputat, 2015). Dari latar belakang tersebut rumusan masalah penelitian: bagaimana implementasi program pengelolaan penyakit prolanis di Puskesmas Ciputat?. Sehingga peneliti ingin meneliti implementasi program pengelolaan penyakit kronis di Puskesmas Ciputat. Tujuan penelitian ini adalah untuk menganalisis implementasi prgram pengelolaan penyakit kronis di wilayah 
kerja pusat kesehatan masyarakat Kecamatan Ciputat.

\section{METODE PENELITIAN}

Jenis penelitian ini adalah deskriptif Kualitatif dengan Pendekatan studi kasus. Data primer diambil dengan wawancara terstruktur pada Informan Penelitian. Validitas menggunakan triangulasi data. Peneliti ini dilaksanakan di Wilayah kerja pusat kesehatan masyarakat Ciputat mulai dari bulan Maret 2019 Hingga Juli 2019. Informan kunci pada penelitian ini adalah pemegang program dan atau penanggungjawab program dan pelaksana program. Instrumen utama pada penelitian ini adalah peneliti sendiri. Peneliti juga membuat pedoman wawancara terstruktur. Untuk memudahkan proses wawancara maka peneliti menggunakan alat bantu perekam suara, survei kit. Validitas data menggunakan triangulasi. Pedoman wawancara di uji dengan konstruk validitas. Analisis data menggunakan konten analisis.

\section{HASIL PENELITIAN}

\section{Manajemen Program Pengelolaan}

\section{Prolanis Di Puskesmas Ciputat}

Puskesmas Ciputat merupakan salah satu puskesmas yang ada di wilayah kerja tangerang selatan yang melaksanakan Prolanis. Jumlah peserta prolanis di puskesmas ini mencapai lebih dari 125 peserta. Peserta rata rata sudah stabil dari rumah sakit. Setiap peserta wajib mempunyai buku hijau. Banyak juga pasien yang seharusnya ikut prgram tapi tidak ikut dengan berbagai macam alasan.

“...peserta prolanis kita itu kebanyakan yang kita kelola itu yang sudah stabil dari rumah sakit. Disini yang ga ikut ploranis juga banyak"”... Dia dateng control, tapi tidak rutin setiap bulan" (informan 1) “.... Kegiatan prolanis biasanya dilakukan 1 bulan sekali berupa pemeriksaan gula darah dan tensi, penyuluhan, sedangkan senam 1 minggu sekali. (informan 1)

“... peserta kelurahan Puskesmas Ciputat karena ini Puskesmas lama sudah banyak dari zamannya sebelum ada BPJS artinya yang sudah stabil dari Rumah Sakit Fatmawati dikembalikan ke Puskesmas Ciputat. Jumlah peserta sekarang itu kurang lebih 125an." (informan 1)

Dalam pelaksanaannya peserta prolanis kerap tidak hadir untuk mengikuti program. Peserta yang tidak rutin untuk ikut dalam pelaksanaan kegiatan prolanis akan memicu terjadinya komplikasi pagi penderita dengan risiko tinggi (Abdullah dkk., 2017.). Pada penelitian terdahulu di salah satu klinik di siduarjo juga terdapat hambatan yang hampir serupa dalam menjalankan program pengelolaan penyakit kronis yaitu beberapa peserta Prolanis sering tidak hadir dalam kegiatan 
Prolanis, para penderita diabetes militus tidak terjaring secara maksimal (Susanti, 2018). Dalam penelitian lainnya ditemukan perserta tidak bersedia mengikuti program (Assupina dkk., 2013). Dalam penelitian lainnya terkait pengalaman pasien terkait program prolanis salah satu hambatan tidak berpartisipasi program yaitu adanya keterbatasan fisik untuk menghadiri acara prolanis. (Hatmanti; Rusdianingseh, 2018). Dalam penelitian lainnya yang dilaksanakan di Puskesmas Jetis Kota yogyakarta terkait antusiasme peserta sudah cukup baik dengan mengikuti prolanis. Hal tersebut juga terlihat dari upaya peserta untuk menjaga kesehatan dan mendapatkan pengetahuan dari program pengelolaan penyakit kronis (Meiriana dkk., 2019).

\section{Pelatihan Manajemen program pengelolaan Penyakit Kronis}

BPJS pernah memberikan pelatihan berupa penyampaian materi terkait hipertensi dan DM. "pernah, dari BPJS yang mengadakan. Hipertensi dan diabetes mellitus." Namun untuk petugas prolanis belum diberikan pelatihan terkait manajemen prolanis. Baik berupa peinputan data surveilans prolanis.

“tapi untuk manajemennya belum”. "ya belum. surveilans belum terlibat, padahal itu penting. Kadang-kadang surveilans itu dengan urusannya masing-masing, tetap di LB1.
Surveilans kayanya ga aktiflah."

(informan 1)

\section{Sistem pencatatan pelaporan dan indikator keberhasilan program}

Tidak ada form khusus untuk pencatatan pelaporan program prolanis. Pemeriksaan kesehatan hanya di tulis tangan di buku catatan saja atas inisiatif petugas prolanis. Setelah itu data di input ke $P$ care. Maka akan sangat sulit jika jika ingin mengetahui data kohort per pasien.

“Ga ada, Cuma kita buat saja” iyaa disini aja. Nama, nomor BPJS, nomor telpon, berat badan, tinggi badan, gulanya ada di petugas laboratorium hasilnya"

Data dari hasil cacatatan pemeriksaan yang ditulis oleh petugas prolanis secara inisiatif tersebut akan di input ke $P$ Care. Data tersebut juga di di input ke laporan PTM.

"kalo kemarin PTM itu sempat mendata pasien DM baru setelah itu kita catat"

Belum pernah dilakukan analisis univariat untuk melihat trend kasus dari peserta BPJS. Selain itu belum ada indikator keberhasilan dari program ini secara subtantif baik dari program penyuluhan (peningkatan pengetahuan), senam dan ukuran epidemiologi penyakit seperti fatality dan morbidity. Indikator keberhasilan hanya diukur dari kepesertaan saja. 
"kalo indikator keberhasilan saya adalah pasien saya tidak ada yang gagal ginjal. Itu menurut saya ya. Penyakit kronisnnya dapat ditangani dan dia tidak sampai cuci darah. Kalo dari BPJS sendiri adalah semakin banyak peserta pronalis. Sebenarnya BPJS sasarannya adalah untuk penyakit kronis. Jadi dari pasien saya yang selalu saya katakan adalah pola hidup, makan dan minum obat teratur supaya mereka tidak sampai cuci darah. Itu yang selalu saya katakan dalam setiap penyuluhan, dan mereka mengerti. Kebetulan rata rata pasien prolanis adalah orang-orang dulu yang hebat lah. Jadi mereka mencoba untuk mengerti" (informan 1).

\section{Kesadaran FKTP Swasta memberikan data ke FKTP Pemerintah}

Puskesmas sebagai FKTP Pemerintah mempunyai tanggungjawab terhadap status kesehatan masyarakat di wilayah kerjanya. Di wilayah kerja tangerang selatan khususnya ciputat terdapat FKTP FKTP swasta yang menjalankan program prolanis. Namun belum ada kesadaran memberikan datanya ke puskesmas. Hanya memberikan data ke BPJS melalui $P$ care. Padahal yang bertanggungjawab dan yang harus mengetahui dan melaporkan terkait analisis situasi kesehatan adalah puskemas ke jenjang yang lebih tinggi yaitu dinas kesehatan. Maka disini ditemukan missing dan tidak teringrasi pencatatan pelaporan situasi kesehatan. Di BPJS sendiri melakukan pertemuan kepada FKTP swasta dan pemerintah. Disitu lah baru ada diketahui masalah masalah yang ada di setiap FKTP namun belum ada pelaporan formal.

"terkadang, beberapa bulan sekali ada pertemuan. Ntah dari puskesmas, rumah sakit, penanggung jawab ke kantor BPJS. Nah disana mereka mengeluarkan keluhannya. Nah biasanya dari sana” (informan 2)

Hal tersebut bisa dikarenakan SOP yang belum ada. FKTP melaporkan juga ke dinkes.

"nah biasanya dinas. Mereka yang lapor ke dinas, jadi ga dari kita.” "iyaa. Kan masing masing. Kalo dari kita, Cuma prolanis kita aja. Kita ga pernah ngelaporin prolanis dari tempat lain” (informan 2)

\section{PEMBAHASAN}

Pemerintah Indonesia telah melakukan upaya fasilitasi pelayanan penanggulangan dan pengelolaan Prolanis yang sesuai dengan peraturan presiden nomor 12 tahun 2013 tentang jaminan kesehatan pasal 21 ayat 1 , yang berbunyi salah satu manfaat yang didapat oleh peserta BPJS yaitu pelayanan promotif dan 
preventif salah satunya prolanis. (Putri AE, 2014) Prolanis merupakan salah satu program BPJS Kesehatan dalam rangka pemeliharaan kesehatan bagi peserta BPJS Kesehatan yang menderita penyakit kronis untuk mencapai kualitas hidup yang optimal dengan biaya pelayanan kesehatan yang efektif dan efisien. Bentuk pelaksanaan prolanis yang tercantum dalam panduan praktis Prolanis yang dikeluarkan oleh BPJS Kesehatan, yaitu: (1) Konsultasi medis peserta prolanis; (2) Edukasi kelompok prolanis; (3) Reminder melalui SMS Gateway; (4) Home visit; (5) Aktifitas Klub; dan (6) Pemantauan status kesehatan.

Dalam penelitian ini didapatkan hasil bahwa tenaga kesehatan yang menjalankan program belum mendapatkan pelatihan dari segi manajemen baik dari segi surveilans, pencatatan pelaporan. Hasil penelitian ini Senada dengan penelitian yang pernah dilakukan dilakukan oleh utomo, RN (2019) tenaga terlatih untuk program prolanis di puskesmas pandanaran masih kurang. Dalam penelitian terdahulu juga yang pernah dilakukan di dokter keluarga dijelaskan bahwa bahkan kekurangan tenaga hanya ada PIC 1 orang (Assupina, M, Misnaniarti, Rahmiwati A, 2013). Dalam penelitian yang lain juga ditemukan terkait program ini sumber daya masih kurang baik dana dan tempat. (Rosdiana et al, 2017). Penelitian lainnya terkait implementasi program PROLNIS di
PKM Jogyakarta ditemukan hambatan keterbatasan SDM (Meiriana A, trilaksono L, Padmawati RS, 2019). Pelatihan kerja berpengaruh positif dan signifikan terhadap kompetensi dan kinerja karyawan. (Aditya et al, 2015). Sumber daya manusia sangat menentukan berhasilan suatu lembaga. Maka lembaga harus memperhatikan kinerja agar lebih produktif, efektif dan efesien (Susan E, 2019).

Hasil dari penelitian ini juga didapatkan hasil bahwa tidak ada indikator keberhasilan secara subtantif di bidang management dan ukuran epidemiologi penyakit. Namun dari pada itu, BPJS sendiri telah menetapkan dalam salah satu tujuannya indikator yang ada pada saat ini iyalah indikator $75 \%$ peserta terdaftar yang berkunjung ke Faskes Tingkat Pertama memiliki hasil "baik" pada pemeriksaan spesifik terhadap penyakit DM Tipe 2 dan Hipertensi sesuai Panduan Klinis terkait sehingga dapat mencegah timbulnya komplikasi penyakit. Dari penelitian sebelumnya yang dilakukan oleh putro (2019) menyatakan peserta prolanis hipertensi yang masih belum memenuhi indikator keberhasilan Prolanis yaitu $75 \%$ peserta yang terdaftar. Dari penelitian sebelumnya pun terkait indikator kepesertaan masih belum tercapoai $75 \%$ (Rosdiana et al, 2017). Hasil penelitian lain yang dilaksanakan di Kabupaten Pekalongan untuk implementasi prolanis 
belum ada standar operasional prosedur (Sitompul, S., Suryawati, C., \& Wigati, P. A. 2016).

Dari hasil penelitian diatas didapatkan hasil bahwa FKTP swasta belum ada kesadaran dalam memberikan hasil temuannya di FKTP pemerintah dalam hal ini juga terkait management program. Hal ini senada dengan penetian yang dilakukan oleh susanti (2018) bahwa terdapat hambatan kurangnya koordinasi dan kerjasama antara faskes 1 dan faskes 2 .

\section{KESIMPULAN}

Kesimpulan dari penelitian ini diantaranya belum adanya pelatihan manajemen khusus prolanis bagi petugas seperti sistem surveilans, tidak ada indikator keberhasilan program yang terukur, belum ada SOP pelaporan dan FKTP swasta tidak ada kesadaran untuk melaporkan data ke puskesmas.Peneliti menyarankan untuk mengadakan pelatihan manajemen pengelolaan penyakit kronis, membuat tools untuk mengukur keberhasilan program serta membuat loka karya untuk membahas SOP pelaporan terkhusus dari FKTP swasta ke pemerintah dalam hal ini puskesmas.

\section{SARAN}

Peneliti menyarankan untuk mengadakan pelatihan manajemen pengelolaan penyakit kronis, membuat tools untuk mengukur keberhasilan program yang lebih subtantif serta membuat loka karya untuk membahas SOP pelaporan terkhusus dari FKTP swasta ke pemerintah dalam hal ini puskesmas.

\section{DAFTAR PUSTAKA}

Abdullah, Sjattar EL, Kadir AR. (2017). Faktor penyebab terjadinya penurunan jumlah kunjungan peserta program pengelolaan penyakit kronis (Prolanis) di Puskesmas Minasa Upa Kota Makassar. Jurnal Ilmiah Kesehatan Diagnosis. Vol. 11. No.4. hal 382-387.

Aditya et al. (2015). Pengaruh pelatihan terhadap kompetensi dan kinerja karyawan. Jurnal Administrasi Bisnis (JAB). Vol. 27 No. 2. hal 1-6.

Assupina, M, Misnaniarti, Rahmiwati A. (2013). Analisis implementasi program pengelolaan penyakit kronis (PROLANIS) pada dokter keluarga PT. ASKES di Kota Palembang tahun 2013. Jurnal ilmu kesehatan masyarakat. Volume 4, Nomor 03.

Badan Penelitian dan Pengembangan Kesehatan Kementerian Kesehtan RI. (2013). Riset Kesehatan Dasar: Riskesdas 2013. Jakarta : kemenkes RI.

Badan Penyelenggaraan Jaminan Sosial BPJS Kesehatan. (2014). Panduan Praktis PROLANIS (Program Pengelolaan Penyakit Kronis). BPJS Kesehatan. Diunduh dari www.depkes.go.id pada tanggal 20 Sepetember 2019 pukul 10.00 WIB.

Hatmanti NM, Rusdianingseh, (2018). Pengalaman pasien Diabetes tipe 2 tentang implementasi prolasi BPJS Kesehatan. the indonesia journal of public health. Vol. 10 no. 2 hal. 8084. 
Meiriana A, trilaksono L, Padmawati RS, . (2019). Implementasi program pengelolaan penyakit kronis pada penyakit hipertensi di Puskesmas Jetis Kota Yogyakarta. Jurnal kebijakan kesehatan Indonesia: JKKI. Vol. 08. No. 2. Hal. 51-58.

Putri AE. (2014). Paham JKN; jaminan kesehatan nasional. Fried-Ebertstifung kantor perwakilan Indonesia. Cetakan I. Hal 9.

Putro G. (2019). Analisis manajemen program pengelolaan penyakit kronis (Prolanis) hipertensi di Klinik Pratama Dinayla Utama 84. Jurnal Manajerial Bisnis. Vol. 2. No. 2.

Puskesmas Ciputat .(2015). Profil kesehatan puskesmas tahun 2015. Tangerang Selatan.

Rosdiana et al. (2017). Implementasi Program Pengelolaan Penyakit Kronis. HIGEIA 1. 3. Hal 140-150.

Sitompul, S., Suryawati, C., \& Wigati, P. A. (2016). Analisis pelaksanaan program pengelolaan penyakit kronis (PROLANIS) BPJS Kesehatan pada dokter keluarga di kabupaten pekalongan tahun 2016. Jurnal kesehatan masyarakat. Vol. 4. No.4. 145-153.

Susan E. (2019). Manajemen sumber daya manusia. Jurnal manajemen pendidikan Islam. ADAARA. Vol. 9 no. 2 hal. $952-962$

Susanti. (2018). Kualitas pelayanan pengelolaan penyakit kronis (PROLANIS) pasien diabetes militus di Klinik Prima Medika Siduarjo. Jurnal Manajerial Bisnis Vol. 1. No. 3. Hal 226-239

Utomo, RN. (2019). Input Program pengelolaan penyakit kronis di Puskesmas. Higeia journal of public health research and development. HIGEIA 3 (1) (2019).

Warganegara E, Nur NN. (2016). Faktor Risiko Perilaku Penyakit Tidak Menular Majority. Volume 5. Nomor 2. Hal $88-94$. 